\title{
THE EFFECTS OF POLITICAL PARITIES ON WOMEN'S ORGANIZATION
}

\section{M.A. Dilshad SABRI ALI}

University of Soran, Faculty of Arts, Department of Sociology, dilshad.ali@soran.edu.iq

\section{Article history: \\ Accepted 30 October 2019 \\ Available online 31 April 2020}

\section{Keywords:}

Women's Organizations,

Political Parties,

Radical Feminist

Liberal Feminist.

\begin{abstract}
A b s t r a c t
The aim of this research is to analyze statistics to understand the effect of political parties on women organizations and the obstacles they create for these organizations as they work for gaining their members' rights. In the research, the quantitative method was used for collecting data, using a questioner. The research participants were chosen through snowball sampling in Erbil Governorate. The size of the sampling was 195 persons that their level of education was different. For analyzing the collected data SPSS software was used. The findings show that politics to a very low extent were obstacles for women's organization and thus these organizations were unable to effectively operate in obtaining their members' rights. The results also show that women themselves were unable to play an effective role for gaining their rights. In addition, the findings show that not having their own sources of finance makes women's organizations depend on political parties.
\end{abstract}

\section{Introduction}

Generally, several civil organizations and groups are founded in every community; these groups are usually established by a group of people in order to serve and provide aids to their members in gaining their rights (Muhseni, 2002: 194). This viewpoint can also imply for women organizations or the feminist organizations as organizations that aim to achieve rights of equality in the roles and responsibilities between women and men either inside and outside the family. Thus, it can be phrased that women organizations strive for achieving equal rights to those of men. Abdul (2011) believes that women organizations have become a means for raising the level of public awareness about women's rights since before such organizations were born and were not entitled to any obvious right or decision in the different political, cultural and socioeconomic aspects in their daily lives in comparison to men. With the appearance of these organizations, they concentrated all their efforts for achieving women's rights, changing the society and eradicating every type of oppression such as gender discriminations that are noticed in the society's roles and responsibilities (Salih, 2005: 22).

Therefore, it can be stated that feminism emphasized that women throughout history have been subjected to oppression and violence in the patriarchal societies, for example, such as inequalities in the rights of expression, working markets, political roles and even in marriage choices between women and men (Abott et all., 2006: 32). Inside Kurdish society (including the Iraqi Kurdistan Region), these organizations have come to existence more regularly or systematically following the establishment of the Kurdistan Regional Government in 1991, even though several organizations and individual women already had been striving for the achievement of women's rights. In this regard, Qadir states that several organizations have been founded after the 1991, up-Rising to advocate the rights of women. However, Qadir believes that without the political parties' support, particularly in terms of financial supports, these organizations would have not been able to settle a single minor problem for women (2009: 48). Based on this perspective, it can be stated that women organizations in the Kurdish society are not independent economically, culturally, socially and so far. Consequently, this dependency of the organizations creates a challenge ahead of securing their rights as well as the decisions that are to be made within the frame of the political parties, not in favor of for women themselves. Through this point of view, it can be noted that women organizations in all societies in general and in the traditional societies in particular have faced several challenges in acquiring their rights equal to that of men. The most noticeable challenge referred to in this research is the impact of 
the political parties or the politicization of women organizations, especially by men because most of the authorities of the communities, especially in the traditional communities, are in hands of men and these authorities are exploited by the men for their benefits socially and politically.

\subsection{Research problem}

Feminism as a social movement strives for achieving women's rights and these strives could be through some institutions such as women organizations. Therefore, in the communities, especially the communities with cultural patriarchal superiority, most of the social or political authorities remain under the power of men; this leads them to use most of the rights and responsibilities for their own benefits and to impose impact on the women, especially in making political decisions since the men deem women as compliant personalities committed to fulfil men's orders and decisions. As a result, women in the patriarchal communities cannot develop their abilities or take part in running the community's affairs the same as men, because women's deviations from any of the society's traditions will negatively impact them and they will become victims of the beliefs the women organizations work for. Consequently, women in such communities forcefully choose silence because, otherwise, they will be subject to risks and often fall victim because of their efforts for achieving their rights in the community (Hassan, 2010: $41)$.

Following the up-rise in 1991 when the political parties founded the Kurdistan Regional Government, it did not last long when a civil war broke out between the two politically dominant parties of the Kurdistan Region. This left effects on the whole components and institutions of the community. One of these components was that women organizations; too, divided on the Region's political parties. In other words, women organizations were enrolled under the umbrella of the political parties, causing them to totally lose their independency and become a part of the dominant patriarchal culture as these political parties have been run under influence of men.

This patriarchal dominance has spread its ideology among the political parties completely, thus bringing women organizations under its control and its manly thinking. It is obvious that the rights of women are limited in patriarchal communities and even these rights are determined by men. This has clearly reflected in the Kurdistan Region's women's organizations. Also, Qadir believes that in traditional and patriarchal communities, of which the Kurdistan Region can be an example, women's organizations fall under the influence of the political parties. In other words, these organizations make integral parts of the political parties run by men. (2009: 48).

\subsection{Research question}

- To what extent do political parties hinder women's organizations from achieving their rights?

\subsection{Hypothesis of the Research}

There is an important statistical connection between literacy and affiliation to political parties as a challenge in front of women's organizations in achieving their rights.

\subsection{Aim of the Research}

The aim of the researcher is to know about the factors and challenges ahead of women's organizations in their efforts for achieving rights equal with men in daily life roles and responsibilities, such as the obstacle of the political parties in the Kurdistan Region.

\section{Literature review}

\subsection{The background of the feminist movement}

The essential goal of a feminist organization or a women's organization is to guarantee civil rights such as removing the obstacles for getting married, education, participation in the work market and in the politics in the community (Beasley, 2005: 30).

The feminist organizations' goal is to defend the aforesaid rights for feminism itself. This is an outcome of the differentiations and discriminations witnessed in the different communities; and their essential goal is to insure gender equality between women and men; in other words, women and men culturally are entitled the same rights. Though the concept of feminism does not have a long history in the Kurdistan Region, it has appeared just after 1991, but it dates very long in the western communities. Thus, Salih thinks this concept sources from the Latin word of Femina which means "women" (2005: 22). Readings of the feminism concept by the counters or the anti-women movements which support conservative concepts of which patriarchy is an element probably is more toward underestimating feminist organizations as they see the feminist organizations threatening the social stability. But in fact, as referred by some references, feminism is meant by the achievement of women's rights in roles and responsibilities scientifically and equally with men (Beasley, 2005). Before the establishment of these organizations, particularly in communities as the Kurdistan Region where patriarchy is dominant, such rights including participations in business and political activities, freedom of expression, etc. are deprived from women to a large extent because of the norms and traditions of the communities where men impose their wills. It is worth mentioning, women's organizations in such circumstances cannot freely claim their rights as they would face repression and violence once their claims contradicting the will of the political party supporting 
them or whenever contradicting the Kurdish community norms and traditions (Qadir, 2009: 62-63).

But following the appearance of the feminist movement in the form of organizations, this point of view also changed a great deal as these organizations exerted efforts for raising the awareness of women to defend their rights, to release themselves from under the influence of the political parties in which men are mostly dominant and to dedicate in favor of the women. However, Hassan (2010: 24) says whenever women have their own opinions and work for the benefit of their interests, they would face several challenges especially from the political parties. For the same reason, whenever the role of women's organizations are discussed, most of those who hold opposing interests think that these organizations harm the harmony of the community. In this regard, the feminist Suzan Antony says: "women will be beheaded if they do not obey men." She means that if the women express themselves in a way opposing the will of men or beyond the limits determined for them, then they will be silenced and abstracted from power. As it was in the middle age western communities, the women who would claim their rights beyond the common social values and norms, they would have been called as seditious or witches and subjected to the execution of burning by the church authorities (Mahmood, 2018).

Hence, it can be stated that throughout the history whenever women's organizations have tried to prove that women's abilities can be invested in the society the same as men, they would have been opposed by the opposing gender. Also, it is noticed that the political parties that are mostly run by men direct women's organizations in favor of their own interests and of their political parties. In another side, Salih (2005: 43) believes that the Kurdish feminist movements at the current time are inactive movements with no self-determination because if they were under the influence of men in the past, now they are subordinated by the thinking of the political parties and the rulers.

\subsection{The political parties and women organizations}

The impacts of political parties on women's organizations involve women's organizations within political parties is a complicated and widespread process involving many of the organizations, groups and centers. Women's organizations can be referred to as an example of being subject to the wave of enrolling them within the political parties especially in the traditional societies. Therefore, these organizations cannot manage their affairs regularly and independently, because they are not allowed by the political parties to help women if not in the interest of the party itself. Therefore, it can be stated that involvement in the political parties is one of the challenges in front of these organizations, disabling them to defend the rights of their women members. Also, Salih thinks that the political parties in the Kurdistan Region have not allowed these organizations to undertake their duties independently and freely because they classify the interests of women within the interests of the political parties and leaders. However, the women's organizations, because of their loyalty to their subordinator political parties in which the will of men is dominant, have disappointed women in achieving their rights. At first, they started with the slogan that they will work for the benefit of women and for achieving their rights from men, but this turned otherwise (Salih, 2005).

It might be normal for any political party to have a subordinated women's organization the same as it is in most of the communities and the same as the political parties in the advanced western countries. At the same time, women do not much commit to the will of their parties since they adhere their own policies and work according to their own interests. Though there are women's organizations in the Kurdistan Region, yet they act according to the will and program of their political parties; this is because of the few numbers of women in the decision-making positions and consequently the women cannot have noticeable influence and make decisions in favor of women themselves (Siddiq, 2005).

Still, sometimes women themselves can make challenges ahead of these women's organizations in achieving their rights because of the lesser number of women in comparison to men in the activities of the organizations in the Kurdistan Region. Also, this low rate of women in the political parties and in their activities probably is because of the reticence of the culture and tradition in the Kurdistan Region since the Kurdish culture in a great extent is a patriarch culture that does not allow much opportunities to oppose gender to activate in equal levels. Furthermore, Siddiq believes that these organizations subordinated to the political parties cannot equally achieve women's rights, especially in the right of developing a comprehensive program for their own; in another word, they cannot draft their own policies without the interference of men in the political parties (2005: 12). The radical feminists believes that if the patriarch authority collapses in the communities, then women and men can play equal roles in their daily lives. This is because they think that the reason of suppressing women and not allowing them fair and equal opportunities returns to the influence of men in the patriarchal communities (Abbott et al., 2006: 35).

According to this opinion, in the traditional communities, particularly in the Kurdistan Region and more particularly in the dominant political parties, the rate of the women's presence must be equal or even higher than men in order not to allow this absolute authority in the hands of men who often position women 
under influence of the opposite gender or being oppressed. In another word, this is a must for the vital decisions not only to be made by men under the excuse of political and social interests, but equally be in favor of both genders. Thus, women will not be deemed as a week creature by the opposite gender. Meanwhile, the liberal feminists believe that reforms must be comprehensively done in all aspects of the community including the legal, social and educational aspects so as equally is fully achieved among the community members and the whole aspects of the community are run equally by women and men (Abbott et al., 2006: 32). Based on this point of view, this reform is implemented in the community and particularly inside the political parties, then women in general and the women organizations in particular will be able to freely and independently manage their affairs and gain their rights.

\section{Methodology}

\subsection{Quantitative Method}

For any research, more than one research method can be used. Weaknesses and strengths of the methods must be estimated prior in identifying the method appropriate for the research, which the researcher intends to produce. The method used in this research is the quantitative method which is specialized for working based on numbers, tables and images for presenting the research results and for showing their relations with the assumption. Through quantitative method, questionnaire tools can be used for collecting the data needed by the researchers for conducting the research (Bryman, 2012). The reason behind choosing this method by the researchers returns in one hand to the importance of the study subject and in the other hand it has been attempted to investigate the subject in a value's quantitative way for the purpose of gaining accurate information. In term of place, the community subject of this research is Erbil Province and the number of research participants in this study are 195 respondents.

\subsection{Type of the Research Sampling}

In this research, snowball sampling has been used through which the researcher attempts to find the required number of the research participants. As the researcher does not have access to a list of the participants and they cannot be found randomly, this sampling is regarded as non-random (Kumar, 2011: 208). In the first hand, the researcher collects information from a small number of participants whom he thinks have knowledge about the subject of the research. Then, the participants are asked to introduce more participants on the same subject. It means that the first wave of the participants will lead to a larger number of participants. The researcher, then, will find the participants guided by the previous participants to ask them the same questions and thus introduced to the required number of the participants (Omer, 2011:242).

\subsection{Data Collection}

For obtaining data in this research, the researcher has depended on using questionnaires for which direct meetings are held with the research participants. After gaining the participating samples' consent for meeting and after explaining the purpose of the research to the participants, the questionnaire was distributed on them as they were volunteer participants. The researcher then has collected the questionnaire forms that have been filled by the participants. The answered and received questionnaires were 195 forms. The questionnaires have been reviewed for making sure about that they answered properly and no questions were missed, and also they have been numbered. After checking the questions one by one, the answers were entered into the SPSS program for the purpose of analyzing the gained information. SPSS is a statistics software for quantitative data and the research results are shown in numbers, tables and images (Landanu and Everitt, 2004). The reason behind using questionnaire tools in this research returns to some advantages such as time and financial efficiency among the methods used for collecting the information, the swiftness of collecting the information and also it is easy for analyzing the similarities and the differences between the outcome variables (Bryman, 2012).

\subsection{Ethical Issue}

In a field research, the researcher must consider a number of issues. For this research, the researcher has tried to gain consent of the participants to voluntarily become research participants and to distribute and receive back the questionnaire in the appropriate time so as not to waste their times. Also, the research participants have been assured that the given information will be kept by the researcher until they are used for the research; afterwards the information will be destroyed. Opportunity has been given to the participants, if required, to give borrowed private information about themselves if they expect negative impact on their personality. Also, it has been tried not to address sensitive questions in the questionnaire in order to avoid leaving negative effects on the participant's personality, position and thinking while taking part in this study.

\section{Findings and Discussions}

This research attempts to conduct an analysis about the influence of political parties on women's organizations as the research samples consist of (195) people from different levels of literacy/education. 
Figure 1. Explanation of literacy levels

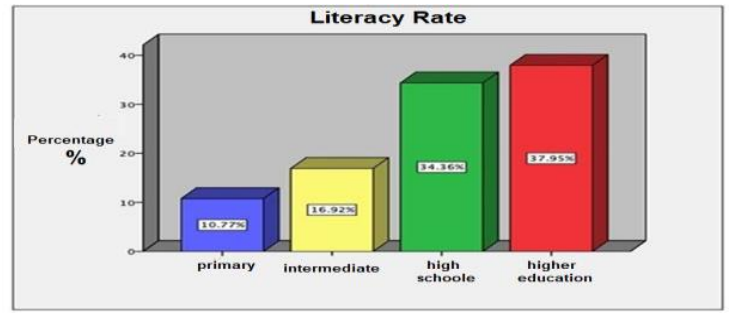

Image 1: shows the literacy levels of the research samples which consist of (195) people. A rate of $37.95 \%$ are with higher education level, a rate of $34.36 \%$ are with high school educational level while intermediate level makes $16.92 \%$ and primary level makes $10.77 \%$ of the whole samples. The image clarifies that the literacy and education levels of the participants are different.

Table 1. Relations between education levels and the reasons behind failure of achieving women's rights by the women's organizations.

\begin{tabular}{|c|c|c|c|c|c|c|}
\hline Chi-Square Test & Total & Patriarchy & $\begin{array}{c}\text { Political parties } \\
\text { influence on } \\
\text { organizations }\end{array}$ & $\begin{array}{l}\text { The women } \\
\text { themselves }\end{array}$ & & \\
\hline \multirow{5}{*}{$\begin{array}{c}\text { Chi-Square }=1.990^{\mathrm{a}} \\
\text { Phi }=.101 \\
\text { Cramer's V }=.071 \\
\text { P-value }=.921\end{array}$} & $\% 100$ & $\% 57.1$ & $\% 14.3$ & $\% 28.6$ & Primary & \\
\hline & $\% 100$ & $\% 54.5$ & $\% 18.2$ & $\% 27.3$ & Intermediate & \\
\hline & $\% 100$ & $\% 46.3$ & $\% 19.4$ & $\% 34.3$ & High School & $\overline{0}$ \\
\hline & $\% 100$ & $\% 51.4$ & $\% 13.5$ & $\% 35.1$ & $\begin{array}{l}\text { Higher } \\
\text { Education }\end{array}$ & مू \\
\hline & $\% 100$ & $\% 50.8$ & $\% 16.4$ & $\% 32.8$ & Total & \\
\hline
\end{tabular}

The main goal of the women's organizations is to insure the women's rights and achievement of equality in rights and responsibilities between women and men. Henceforward, Qadir (2009) thinks that women and organizations defending the women's rights face persecution whenever they strive for achieving their rights independently and in contrast to the will of the political parties and against the patriarchal norms of the community. As noticed, the participants of this research are from different levels of literacy and education, the levels of primary, intermediate, high school and higher education. Nearly $52 \%$ of the participants think that patriarchy hinders the achievement of women's rights.

The answers of those who think that it is because of women themselves who cannot play an effective role in the community make a rate of $32 \%$ of the total. However, no obvious difference of the answers of the participants of different literacy levels is noticed in regard whether the involvements within the political parties challenge the achievement of women's rights; their answers make a rate of $20 \%$ which is the lowest rate. In this regard, Salih (2005) believes that the political parties have not allowed women parties to act independently and away from the parties' interests. Meanwhile, the research participants' answers mark that political parties have the least effect in hindering the achievement of women's rights. Here, we conclude that the members and supporters who work in these organizations have the same thinking as the thinking and policies of the political parties.

The noticeable answers of the research participants in regard of the hindrance of patriarchy ahead of the achievement of women rights by the women organizations makes the highest rate of the answers. This is similar to the thinking of the radical feminists who think that vanishing or weakening patriarchy in the community will become a factor for the accomplishment of balance between women and men in the community; and thus, this will mitigate the possibilities of persecuting women or negatively influencing them. In another side, according to this viewpoint, with the vanishing or weakening of the patriarchal influence, women organizations will be able to act more freely in running their affairs and in achieving the rights of their members since almost the whole part of life in the traditional communities are controlled by the political parties with mostly men dominance.

Here it becomes clear that the P-value makes (.921) which is more than the expected rate which is $(0.05)$ and also the assumption of none-existence is rejected. In another word, there is no statistical relation between the two variables. See Table No. (1) for more information.

Table 2. Relation between literacy levels and decision-making by the organizations

\begin{tabular}{|c|c|c|c|c|c|c|}
\hline Chi-Square Test & Total & \begin{tabular}{|l|} 
In favour of \\
women \\
interests
\end{tabular} & Culturally & $\begin{array}{l}\text { Political } \\
\text { parties' } \\
\text { interests }\end{array}$ & & \\
\hline \multirow{5}{*}{$\begin{array}{l}\text { Chi-Square }=10.862^{2} \\
\text { Phi }=.236 \\
\text { Cramer's V }=.136 \\
\text { P-value }=.285\end{array}$} & $\% 100$ & $\% 66.7$ & $\% 19.0$ & $\% 14.3$ & Primary & \multirow{4}{*}{ 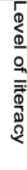 } \\
\hline & $\% 100$ & $\% 54.5$ & $\% 22.3$ & $\% 23.2$ & Intermediate & \\
\hline & $\% 100$ & $\% 67.2$ & $\% 7.5$ & $\% 25.3$ & High School & \\
\hline & $\% 100$ & $\% 68.9$ & \%12.2 & $\% 18.9$ & $\begin{array}{l}\text { Higher } \\
\text { Education }\end{array}$ & \\
\hline & $\% 100$ & $\% 65.6$ & $\% 12.8$ & $\% 21.6$ & \multicolumn{2}{|l|}{ Total } \\
\hline
\end{tabular}

As Beasley (2005) puts it, the prior goal of women's organizations emphasize the achievement of the civil rights and removing challenges in front of women's life areas such as marriage, education, participation in business, and in political life. Accordingly, women's organizations must make decisions in favor of their members. Hence, this research asks the participants whether to and what party their decision-making is relevant to. as it is known, the participant samples have different levels of education and their opinions are close to each other. More than $60 \%$ think that their organizations make decisions in favor of women's interests. According to the participants' answers, which 
makes the majority, they believe that women's organizations in the Kurdistan Region issue decisions in the interest of their members, not in the interest of the political parties. Those who answered with that the women's organizations make decisions in the interest of the political parties which they are affiliated with make nearly $20 \%$ of the total answers.

This matches with the viewpoint of Salih (2005) who thinks that women's organizations have become followers of the thoughts and mentality of the rulers, and particularly the political parties. Even though, this contracts the opinion of the majority who think that women's organizations act and make decisions in favor of their members. It can be concluded that except for some people in this research like Salih who think that women's organizations have become annexes to the political parties and they cannot significantly act without the will of their political parties, yet the majority of the research participants from the different levels of education have shown the contrary. Accordingly, it shows that the women organizations to a good extent have been able to defend the rights of women and make decisions in favor of women.

As a result, it can be cleared that the P-Value equals (.285) which is higher than the standard level of $(0.05)$; here the assumption of absence is rejected. In another word, there is no statistical relation between the two variables. Look at Table No. (2) for more information.

Table 3. The relation between literacy level and lack of independent financial sources as a reason for dependency of women's organizations on the political parties.

\begin{tabular}{|c|c|c|c|c|c|c|}
\hline Chi-Square Test & Total & Partially & No & Yes & & \\
\hline \multirow{5}{*}{$\begin{array}{l}\text { Chi-Square }=9.242^{\mathrm{a}} \\
\text { Phi }=.218 \\
\text { Cramer's V }=.154 \\
\text { P-value }=.160\end{array}$} & $\% 100$ & $\% 76.2$ & $\% 4.8$ & $\% 19.0$ & Primary & Q \\
\hline & $\% 100$ & $\% 42.4$ & $\% 15.2$ & $\% 42.4$ & Intermediate & \\
\hline & $\% 100$ & $\% 59.7$ & $\% 19.4$ & $\% 20.9$ & High School & $\bar{F}$ \\
\hline & $\% 100$ & $\% 58.1$ & $\% 14.9$ & $\% 27.0$ & Higher Education & है \\
\hline & $\% 100$ & $\% 57.9$ & $\% 15.4$ & $\% 26.7$ & Total & \\
\hline
\end{tabular}

Sometimes, decision-making by women's organizations in favor of their members would be challenged because of their dependency on the political parties, especially financial dependency. In this regard, Siddiq (2005) and Qadir (2009) think that when the organizations follow the decisions of their political parties, then they would not be able to develop a special program for their own in the benefit of themselves and of their members because, as one of the reasons, they financially are dependent on the political parties. To a question whether lack of financial sources for the women's organizations is a reason for their dependency on the political parties, as shown in Table No. (3), the research respondents from the different levels of education have answered by nearly $60 \%$ that financial sources to an extent is a reason for their dependency on the political parties. Nearly $14 \%$ think that financial sources are not a reason for their dependency on the political parties. However, the respondents who answered in (Yes) from all education levels make nearly $26 \%$. This shows that the rate of those who think that lack of financial sources is a reason for women's organizations dependency on politics is more than those who replied by (No) and do not think it as a reason.

As a result of the answers of research participants from the different levels of education it can be figured out that if the women's organizations are dependent on the parties, it is because of lack of independent financial sources. These answers are similar to the opinion of the previous references which state that if the financial sources of the women's organizations are cut by the political parties, the organizations will not be able to conduct any activities for the benefit of the organization or their members. In the traditional communities where most of the decisions and authorities are in the hands of men, financing is always used as a means for subordinating and exploiting the opposite gender.

As a result, it can be cleared that the P-Value equals (.160) which is higher than the standard level of (0.05); here the assumption of absence is rejected. In another word, there is no statistical relation between the two variables. Look at Table No. (3) for more information.

Table 4. The relation between literacy levels and shortening by women organizations in attaining women rights because of their role in the political parties.

\begin{tabular}{|c|c|c|c|c|c|c|}
\hline Chi-Square Test & Total & Partially & No & Yes & & \\
\hline \multirow{5}{*}{$\begin{array}{l}\text { Chi-Square }=17.036^{\mathrm{a}} \\
\text { Phi }=.296 \\
\text { Cramer's V }=.209 \\
\text { P-value }=.009\end{array}$} & $\% 100$ & $\% 66.7$ & $\% 9.5$ & $\% 23.8$ & Primary & 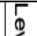 \\
\hline & $\% 100$ & $\% 54.5$ & $\% 24.2$ & $\% 21.3$ & Intermediate & $\frac{w}{0}$ \\
\hline & $\% 100$ & $\% 50.7$ & $\% 41.8$ & $\% 7.5$ & High School & $\bar{F}$ \\
\hline & $\% 100$ & $\% 35.1$ & $\% 44.6$ & $\% 20.3$ & $\begin{array}{l}\text { Higher } \\
\text { Education }\end{array}$ & २ू \\
\hline & $\% 100$ & $\% 47.2$ & $\% 36.4$ & $\% 16.4$ & Total & \\
\hline
\end{tabular}

As Beasley (2005) puts it, the prior goal of the women's organizations emphasizes on the achievement of the civil rights and removing the challenges in front of the women's life areas such as removing marriage challenges, education, and participation in business and in political life. Through looking at answers of the research participants about the question whether the women's organizations disregard defending the right of women, nearly a rate of $30 \%$ have answered with (No) thinking that the women's organizations have not neglected their responsibilities in defending the right of women. Meanwhile, 
those who have answered by (Yes) make about $18 \%$ and they think that the women's organizations have disregarded their responsibilities in defending the rights of women because of the political parties.

This is like the opinion of Siddiq (2005); despite that there are women's organizations in the Kurdistan Region, they act according to the needs and programs of the political parties and their programs are developed by the parties. However those who have answered by (to an extent) make more than 50\%; they make the highest rate among the respondents. This shows that the duties of the political parties are also a factor for the women's organizations not to fulfil their responsibilities in the interest of their members and women in general because the interests of their political parties come prior the interests of women. As mentioned in the previous references of this research, if the women's organizations and women in general act in a way opposite to the interests of the political parties, they will face more problems and challenges in their daily life.

As a result, it can be cleared that the P-Value equals (.009) which is higher than the standard level of (0.05); here the assumption of absence is rejected. In another word, there is no statistical relation between the two variables. Look at Table No. (4) for more information.

\section{Conclusion}

Women's organizations as official organizations have come to existence in the Kurdistan Region following 1991. These organizations have worked either under the influence of the political parties or independently. Therefore, this research attempts to clarify the influence of the political parties on women's organizations. Involvement of the women's organizations within the political parties makes hinderances ahead of the organizations in achieving the rights of women. The research participant who answered the questionnaire are 195 people of different levels of literacy/education. The results of the research show that the political parties in a low rate leave influence on the women's organizations in the Kurdistan Region. However, a major rate of the respondents' answers return the failure in the achievement of the rights of women by the women's organizations to patriarchy, which hinders attaining their rights.

The results of this research show that the answers of the participants are to an extent similar to the opinion of the aforementioned references as they think that the women's organizations are dependent on the political parties because of the lack of financial sources. However, in reply to the question whether the women's organizations in making decisions what aspects do they consider, the majority of the research participants think that the women's organizations make decisions in favor of women, not only in the interest of the political parties. The results of this research shows that women's organizations to a fair extent cannot firmly and independently manage their responsibilities for defending the rights of their members because the political parties politically or financially influence these organizations.

\section{References}

1. Abbott, P. Wallace, C. Tyler, M., (2005), “An Introduction to Sociology, Feminist Perspectives", London and New York: Routledge, 3rd Edition.

2. Abdul, S. (2011), "Feminism movement" Idea magazine, No. 26 pg 153-158.

3. Beasley, C., (2005), "Gender \& Sexuality Critical Theory, Critical Thinkers" London and New Delhi: SAGE. 4. Bryman, A., (2012), "Social research methods", Oxford: Oxford University Press, 4th Edition.

5. Hassan, N., (2010), "Me and you are equal", Erbil: Erbil publication.

6. Kumar, R., (2011), "Research methodology, a step by step guide for beginner", Los Angeles: Sage, 3rd Edition.

7. Landanu, S. and Everitt, B., (2004), “A Handbook of Statistical Analyses using SPSS", Chapman \& Hall/CRC Press LLC: Boca Raton.

8. Mahmood, H., (2018), A brief meaning of historical violence-based on gender. [online]. "culture magazine" Availabe from: http://cultureproject.org.uk/kurdish/genderhouzan-mahmud/ [accessed 05th May 2019].

9. Muhseni, M., (2002), "Introduction to sociology", Translated by Swayli, R., Erbil: Mokeryani publication.

10. Omer, M., (2011), "Research methods of sociology", translated by Rahman, Z., Erbil: Rojhalat publication.

11. Qadir, S., (2009), "The problem of woman in the long history", Erbil: Rojhalat publication.

12. Salih. K., (2005), "Cognitive feminism and Kurdish society", Erbil: Aras publication.

13. Siddiq, A., (2005), "Woman issues and in the new millennium", Sulaimaniya: Ganj publication. 